Clare Mylan

is the head of sales of Gecko. Now in its 16th year, Gecko combines customer journey planning, personalization strategy and data insight tools with digital print capabilities and tailored marketing systems for brand management, stock ordering and campaign management. The company has worked with brands including Mecca, Eurocamp, People's Post Code Lottery and NFU Mutual.

Keywords: personalization, marketing automation, big data, digital print

Mobile home holidays

Enlarged and complex business

\section{Holiday information}

Clare Mylan

Gecko Direct Fairbank House,

1 Moorfield Business Park, Moorfield

Close, Yeadon, Leeds, West Yorkshire LS19 7YA, UK

Tel: +44 (0)1133910704

E-mail: C.Mylan@gecko.co.uk

\section{Case Study}

\section{Gecko improves customer communications for Eurocamp}

\author{
Clare Mylan
}

Received (in revised form): 15th December 2015

\begin{abstract}
This case study looks at how European camping holiday specialist Eurocamp deployed a personalized digital print solution to help it streamline customer communications and improve customer rebook ratings.
\end{abstract}

Journal of Direct, Data and Digital Marketing Practice (2016) 17, 159-162. doi:10.1057/dddmp.2016.1

\section{Background}

Eurocamp, a leading brand of mobile home holidays, operates 180 parcs in 11 European countries. Formerly owned by Cox \& Kings, Eurocamp was acquired by Homair Vacances for £89m in September 2014.

\section{Challenge}

To understand the challenges Eurocamp faces, it is important to look at the last 3 years in the brand's history. While still under the ownership of Cox \& Kings, Eurocamp announced in 2013 that it would be consolidating its Eurocamp and Keycamp brands and would begin selling through travel agents for the first time. This, combined with the company's acquisition by new French parent, Homair, created a vastly enlarged and more complex business that saw the Eurocamp brand take control of 15,000 mobile homes on around 300 campsites, situated principally in France, Spain, Italy and Croatia.

Following the acquisition, Eurocamp found that its newly enlarged business, complete with sub-brands such as Eurocamp Active - a collection of parcs centred around the pursuit of sporting passions - had created a marketing communications challenge that was both timeconsuming and expensive. Before working with Gecko, Eurocamp was sending a wide variety of print communications to its customers in the runup to their holidays to deliver all of the information and items they needed to enjoy their break.

This was often further complicated by the fact that many Eurocamp customers chose to split their break across two or more campsites, sometimes in different countries. The result was a time-consuming mailing schedule, difficult for Eurocamp's marketing team to manage. Eurocamp needed to reduce the number of mailings it was sending to its 
装: Mylan

Reducing mailing volume

\section{Personalized information booklet}

Local area knowledge and activities

\section{Digital printing}

customers without compromising on quality of the information it was providing.

\section{Solution}

The enhancements in digital print and automation technology over the last few years have made complex personalization projects increasingly easy to manage. In a move to consolidate Eurocamp's marketing communications into one mailing and further enhance the customer experience, Gecko and Eurocamp planned a complex information booklet that would be personalized to each customer, providing all the information they would need to get the most from their holiday, whether it was a single or multi-parc booking (see Figure 1).

Gecko designed and delivered an automated marketing solution that linked to Eurocamp's reservation system. Customer details were combined with complex look-up tables, rule engines and an image database to create fully personalized booklets, detailing all aspects of a customers' holiday, with added local area knowledge, available excursions and activities, maps, hints and tips, all relevant to the life stage of the recipient and all delivered pre-departure. All imagery reflected the parc location, type of accommodation booked (tent or mobile home) and featured children or couples depending on the passengers on the booking. The number of pages contained in the booklet depended on the number of parcs the customer planned to visit during their holiday - anywhere from 16 to 48 pages (see Figure 2).

During booking season, Eurocamp's reservation data was sent directly to Gecko throughout the day via a secure portal hosted on Gecko's own automated marketing platform. Gecko's systems picked up the XML feed, converted it to artwork pulling relevant parc details, imagery and travel information into base creative, then output the personalized artwork as a PDF.

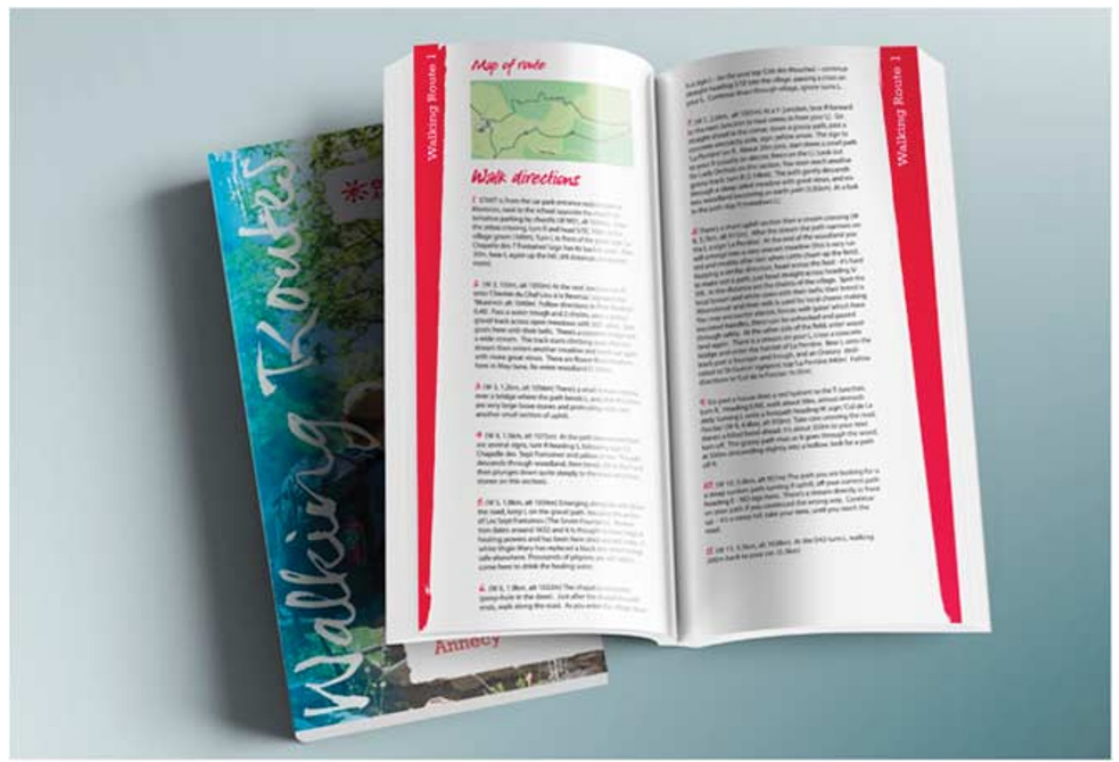

Figure 1: Eurocamp holiday information booklet 


\section{Barcode scanning}

\section{Check-out scans}

\section{PDF by email}

\section{Increased booking rate}



Figure 2: Local activities information

Artwork was queued straight to the digital presses and the booklets were then printed with an individual bar code included at the bottom of each page outside the trim area. A removable cover was also printed containing a fulfilment list of all the items that needed enclosing with the booklet.

A check-out barcode was also included to support the quality control ticketing. Barcode-enabled stitching machines scanned each page as they went through. The codes told the machine when a page was out of order or if there was something missing. If this was the case, the machine stopped and an operator investigated. If no issues were detected, the codes told the machine when all the pages had been collated and the booklet was then stitched and trimmed to remove the barcode at the edge.

Operators then hand-filled the booklet into an outer cover along with any other items needed on the fulfilment list, such as cycling maps/regional maps/GB stickers and so on. The cover was then removed before enclosing. Once the batch was despatched, each cover was scanned to ensure that every booklet had left the building. These check-out scans also provided despatch reports to Eurocamp and allowed the team to keep track of stock levels, alerting them when items needed to be reordered.

During peak season, thousands of booklets per day were processed, but as levels fluctuated depending on time of year, this flexibility had to be worked into the daily schedule. From receipt of data to mailing, booklets took less than 48 hours to turn around. The artwork PDF was also emailed to the customer, so they could have access to their information on their smart devices.

\section{Outcome}

The booklets have had a significant impact on customer loyalty with positive feedback across the board, particularly on social media channels. The company's rebook rating has increased to 93 per cent. In addition, the 
Positive customer feedback automation system has simplified after-sales communication process, removing a layer of administration for agents.

Donna Jeffs, head of creative at Eurocamp, said: 'Our customers have really embraced the pre-departure booklet as a valuable addition to their holiday experience. Combining all of their holiday booking details with local area information and other useful tips has proven to be very popular. It is a great example of what is possible when you combine a reallypersonalised creative and a comprehensive technical solution. While our customer feedback has been positive, we've also seen cost savings from combining several communications into one and, with clever data handling from both parties, the marketing automation technology has reduced the time our customer contact team spend on administration. Gecko has delivered a quality solution that is central to our 2015 customer communications strategy'. 